\title{
Digestibilidade aparente de dietas contendo farelo de cacau ou torta de dendê em cabras lactantes
}

\author{
Herymá Giovane de Oliveira Silva( ${ }^{(1)}$, Aureliano José Vieira Pires ${ }^{(1)}$, Fabiano Ferreira da Silva(1),

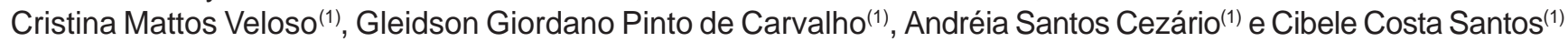 \\ (1)Universidade Estadual do Sudoeste da Bahia, Dep. de Tecnologia Rural e Animal, Praça da Primavera, no 40, CEP 45700-000 Itapetinga, BA. \\ E-mail: heryma@uesb.br, aureliano@uesb.br, ffsilva@uesb.br, cmveloso@uesb.br, giordano113@hotmail.com, deacezario@bol.com.br, \\ cibele_zootecnista@yahoo.com.br
}

\begin{abstract}
Resumo - O objetivo deste trabalho foi avaliar a digestibilidade aparente dos nutrientes de dietas, contendo farelo de cacau (Theobroma cacao L.) ou torta de dendê (Elaeis guineensis Jacq.), em substituição parcial ao concentrado à base de milho e farelo de soja, na alimentação de cabras lactantes. Foram utilizadas cinco cabras da raça Saanen, aos 60 dias de lactação, em experimento delineado em quadrado latino 5x5, com duração de 14 dias, dos quais 10 dias de adaptação e quatro para coleta dos dados. As dietas, formuladas para possibilitar produção de 2 kg de leite por dia, constituíram-se de 36\% de volumoso e 64\% de concentrado. Utilizou-se, como volumoso, a silagem de milho e concentrado padrão, com substituição de $0 \%$, 15\% e 30\% pelo farelo de cacau ou torta de dendê. Houve redução na digestibilidade real da proteína bruta, com a inclusão do farelo de cacau, a 15\% e 30\%. O coeficiente de digestibilidade aparente, do extrato etéreo das dietas com 30\% de torta de dendê, foi maior que o de $15 \%$ de farelo de cacau. Os subprodutos, em razão da digestibilidade aparente, apresentam viabilidade de uso, como alternativa na dieta de cabras em lactação.
\end{abstract}

Termos para indexação: caprino, resíduos, subprodutos.

\section{Apparent digestibility of diets containing cocoa meal and palm kernel cake in lactating goats}

\begin{abstract}
The objective of this work was to evaluate nutrients apparent digestibility of diets containing cocoa (Theobroma cacao L.) meal or palm kernel (Elaeis guineensis Jacq.) cake, which partially replaced corn and soybean meal concentrate in lactating goats feeding. Five Saanen goats, in 60 days of lactation, were used in a $5 x 5$ latin square experimental design, during 14 days, comprehending an adaptation period of 10 days and four days for data collection. Diets formulated to allow milk production of $2 \mathrm{~kg} \mathrm{day}^{-1}$ consisted of $36 \%$ roughage and $64 \%$ concentrate. The roughage used was corn silage and $0 \%, 15 \%$ and $30 \%$ of cocoa meal or palm kernel cake substituted the standard concentrate. There was reduction of crude protein real digestibility with inclusion of cocoa meal (15\% and 30\%). The ether extract apparent digestibility coefficient of diets, with 30\% palm kernel cake, was greater than that of $15 \%$ cocoa meal. The by-products have potential as alternative feed for lactating goats, based on their apparent digestibility.
\end{abstract}

Index terms: goat, residues, by-products.

\section{Introdução}

A alimentação dos animais representa o maior custo da atividade pecuária (Martins et al., 2000), principalmente quando se usa fonte suplementar de alta qualidade nutricional como o milho e o farelo de soja, tornandose necessária a utilização de fontes alimentares alternativas, com melhor relação custo/benefício, sem concorrer diretamente com a alimentação humana.

Os subprodutos agro-industriais surgem como alternativa viável tanto do ponto de vista nutricional como econômico. Conforme Silva et al. (2002), vários subprodutos originados de processamentos nas indústrias, têm potencial de uso, na maioria dos casos, com reduções nos custos da produção.

O farelo de cacau é o subproduto da retirada do tegumento antes da torrefação das sementes, para produção de manteiga ou chocolate (Brasil, 1998). É encontrado no mercado com preços acessíveis, sendo o estado da Bahia responsável por toda produção de cacau do Nordeste e por 69,9\% do Brasil (IBGE, 2004).

Considerando-se que o farelo de cacau representa 10\% da produção das amêndoas secas de cacau (dado 
estimado do Parque Industrial de Ilhéus, Bahia), que foi de 196.788 t no ano de 2000 (IBGE, 2004), estima-se que a produção brasileira desse subproduto foi de $19.678,8 \mathrm{t}$.

Trabalhos recentes têm demonstrado que é possível a substituição parcial de um concentrado a base de milho e farelo de soja por esse subproduto, na alimentação de novilhas (Pires et al., 2002).

A torta de dendê é o produto resultante da polpa seca do dendê, após moagem e extração de seu óleo (Brasil, 1998), que pode ser utilizada como fertilizante ou como componente de ração para animais. A produção brasileira de dendê cresceu de 522.883 para 717.893 t no período de 1990 a 2002, sendo o Norte e Nordeste as principais regiões produtoras (IBGE, 2004).

Segundo Chin (2002), para a torta de dendê obtida com processo de solvente, utilizada como dieta de bovinos, foram obtidos os valores de $65,1 \%, 72,7 \%, 69,7 \%$ e $86,7 \%$ de digestibilidade para matéria seca, matéria orgânica, proteína bruta e extrato não nitrogenado, respectivamente. Quando obtida por prensagem e avaliada em carneiros, a torta de dendê apresentou valores de digestibilidade da matéria seca, proteína bruta, fibra em detergente ácido (FDA) e fibra em detergente neutro (FDN) de 70\%, 63\%, 52\% e 53\%, respectivamente.

Segundo Carvalho et al. (2002), o aumento do teor de fibra, na dieta de cabras em lactação, promove diminuição do conteúdo de nutrientes digestíveis totais e dos coeficientes de digestibilidade aparente da matéria seca, matéria orgânica, proteína bruta, carboidratos e carboidratos não fibrosos, e promove aumento nos coeficientes de digestibilidade aparente da fibra em detergente neutro e da fibra em detergente ácido. O efeito positivo sobre a fibra em detergente neutro e a fibra em detergente ácido, observado nesse trabalho, de acordo com o autor, deve-se, provavelmente, ao aumento nas proporções de volumoso nas dietas, em razão do aumento da digestibilidade ruminal da fibra, promovido pelas condições ruminais que favorecem o desenvolvimento de microorganismos fibrolíticos.

Este trabalho teve como objetivo avaliar a digestibilidade aparente dos nutrientes de dietas que contêm farelo de cacau ou torta de dendê, em substituição parcial ao concentrado a base de milho e farelo de soja, na alimentação de cabras em lactação.

\section{Material e Métodos}

O experimento foi realizado no Setor de Caprinocultura, do Campus Juvino Oliveira, da Universidade Estadual do Sudoeste da Bahia - UESB, na cidade de Itapetinga, BA, no período de setembro a dezembro de 2002.

Foram utilizadas 5 cabras da raça Saanen num experimento delineado, em quadrado latino $5 \times 5$, com duração de 14 dias, dos quais 10 dias foram de adaptação e 4 dias para coleta de dados. As cabras possuíam, em média, 41,66 kg de peso vivo e 60 dias de lactação, e foram alojadas em baias de 1,2x2,1 m (2,52 $\left.\mathrm{m}^{2}\right)$, com piso ripado de madeira, tendo acesso a bebedouro e comedouro individual.

As cabras foram alimentadas duas vezes ao dia, às $8 \mathrm{~h}$ e $15 \mathrm{~h} 30$, receberam água à vontade e foram ordenhadas às $7 \mathrm{~h} 30$ e às $15 \mathrm{~h}$. Os animais receberam dietas isoprotéicas $(13,2 \%)$, formuladas para atender às exigências de manutenção e de produção de $2 \mathrm{~kg} \mathrm{dia}^{-1}$ de leite, segundo o National Research Council (1981). O volumoso utilizado foi a silagem de milho na proporção de 36\%, com base em matéria seca. Os tratamentos constaram da substituição parcial, no concentrado, da mistura do milho e farelo de soja por farelo de cacau (FC) ou por torta de dendê (TD), na proporção de $0 \%$, $15 \%$ e $30 \%$.

Os tratamentos consistiram de silagem de milho e concentrado padrão, silagem de milho e concentrado com 15\% de substituição por farelo de cacau, silagem de milho e concentrado com $30 \%$ de substituição por farelo de cacau, silagem de milho e concentrado com 15\% de substituição por torta de dendê e, silagem de milho e concentrado com 30\% de substituição por torta de dendê (Tabelas 1 e 2).

Tabela 1. Composição (\%) química, com base na matéria seca, dos ingredientes de dietas contendo farelo de cacau ou torta de dendê.

\begin{tabular}{lrrrrr}
\hline Nutriente $^{(1)}$ & Milho & $\begin{array}{c}\text { Farelo de } \\
\text { soja }\end{array}$ & $\begin{array}{c}\text { Farelo de } \\
\text { cacau }\end{array}$ & $\begin{array}{c}\text { Torta de } \\
\text { dendê }\end{array}$ & $\begin{array}{r}\text { Silagem } \\
\text { de milho }\end{array}$ \\
\hline MS & 86,86 & 86,31 & 86,14 & 88,38 & 27,01 \\
MO & 98,92 & 93,55 & 92,64 & 95,57 & 90,04 \\
PB & 8,59 & 47,35 & 13,62 & 14,51 & 7,81 \\
EE & 5,08 & 3,26 & 11,09 & 7,19 & 2,27 \\
FDN & 11,53 & 13,36 & 45,56 & 81,85 & 71,84 \\
FDA & 2,23 & 7,64 & 37,81 & 42,30 & 33,05 \\
CHT & 85,25 & 42,94 & 67,93 & 73,86 & 78,62 \\
CNF & 86,72 & 37,10 & 35,29 & 1,53 & 19,66 \\
PIDN & 16,41 & 4,45 & 52,20 & 49,43 & 19,46 \\
MM & 1,08 & 6,45 & 7,36 & 4,43 & 9,96 \\
\hline
\end{tabular}

(1)MS: matéria seca; MO: matéria orgânica; PB: proteína bruta; EE: extrato etéreo; FNS: fibra em detergente neutro; FDA: fibra em detergente ácido; CT: carboidratos totais; CNF: carboidratos não fibrosos; PIDN: proteína insolúvel em detergente neutro (porcentual da proteína bruta); MM: mistura mineral. 
Para obtenção dos coeficientes de digestibilidade aparente da matéria seca (MS), matéria orgânica (MO), fibra em detergente neutro (FDN), fibra em detergente ácido (FDA), proteína bruta (PB), extrato etéreo (EE), carboidratos totais (CHT) e carboidratos não fibrosos (CNF), utilizou-se o método de coleta total de fezes, durante os últimos 4 dias de cada período. A coleta das fezes foi efetuada com auxílio de lonas de polietileno perfuradas, para separação de fezes e urina. As fezes foram pesadas, acondicionadas em saco de plástico e congeladas a $-10^{\circ} \mathrm{C}$; posteriormente foram descongeladas e homogeneizadas, manualmente, à temperatura ambiente, por animal e período, retirando-se cerca de $10 \%$ do total excretado para análises químicas posteriores de FDN, FDA, PB e EE, conforme metodologia de Silva \& Queiroz (2002).

Os carboidratos totais obtidos, segundo Sniffen \& Van Soest (1992), consistiram das frações de carboidratos fibrosos, considerados como a FDN corrigida, para o seu conteúdo em matéria mineral e proteína (FDNmp), e de carboidratos não fibrosos, obtidos pela subtração da FDNmp dos carboidratos totais.

Os teores de nutrientes digestíveis totais foram calculados pela somatória da proteína bruta digestível, fibra em detergente neutro digestível, extrato etéreo

Tabela 2. Composição (\%) das dietas de farelo de cacau ou torta de dendê, em substituição ao concentrado padrão de milho desintegrado e farelo de soja, e composição química dos concentrados e da dieta total, com base na matéria seca.

\begin{tabular}{|c|c|c|c|c|c|}
\hline \multirow[t]{2}{*}{ Alimento } & \multicolumn{3}{|c|}{ Controle Farelo de cacau } & \multicolumn{2}{|c|}{ Torta de dendê } \\
\hline & & $15 \%$ & $30 \%$ & $15 \%$ & $30 \%$ \\
\hline Silagem de milho & 36,00 & 36,00 & 36,00 & 36,00 & 36,00 \\
\hline Milho moído & 47,58 & 39,38 & 31,35 & 39,54 & 31,43 \\
\hline Farelo de soja & 14,30 & 13,25 & 12,03 & 12,89 & 11,63 \\
\hline Farelo de cacau & 0,00 & 9,23 & 18,47 & 0,00 & 0,00 \\
\hline Torta de dendê & 0,00 & 0,00 & 0,00 & 9,43 & 18,81 \\
\hline \multirow[t]{2}{*}{ Mistura mineral $^{(1)}$} & 2,12 & 2,14 & 2,14 & 2,13 & 2,13 \\
\hline & \multicolumn{5}{|c|}{ Nutrientes no concentrado (\%) } \\
\hline Proteína bruta & 16,65 & 16,63 & 16,40 & 16,21 & 16,37 \\
\hline Extrato etéreo & 3,43 & 3,91 & 5,31 & 4,01 & 3,82 \\
\hline Fibra em detergente neutro & 19,44 & 22,24 & 27,05 & 28,99 & 31,01 \\
\hline Fibra em detergente ácido & 7,06 & 8,28 & 12,52 & 10,81 & 17,35 \\
\hline Carboidratos totais & 74,90 & 73,69 & 72,06 & 76,63 & 74,23 \\
\hline Carboidratos não fibrosos & 58,00 & 55,03 & 50,45 & 50,63 & 47,44 \\
\hline \multirow[t]{2}{*}{$\mathrm{PIDN}^{(2)}$} & 9,65 & 15,53 & 25,28 & 17,68 & 20,38 \\
\hline & \multicolumn{5}{|c|}{ Nutrientes na dieta total $(\%)^{(3)}$} \\
\hline Proteína bruta & 13,20 & 13,31 & 13,28 & 13,40 & 13,58 \\
\hline Extrato etéreo & 3,49 & 3,81 & 4,72 & 3,87 & 3,76 \\
\hline Fibra em detergente neutro & 35,63 & 37,65 & 40,86 & 41,99 & 43,42 \\
\hline Fibra em detergente ácido & 16,10 & 16,99 & 19,78 & 18,60 & 22,97 \\
\hline Carboidratos totais & 76,18 & 75,40 & 74,34 & 77,32 & 75,74 \\
\hline Carboidratos não fibrosos & 44,87 & 42,77 & 39,72 & 39,96 & 37,76 \\
\hline PIDN & 13,03 & 16,88 & 23,26 & 18,31 & 20,06 \\
\hline
\end{tabular}

(1) Mistura comercial completa (70\%) + farinha de osso (30\%). (2)Proteína insolúvel em detergente neutro: porcentual da proteína bruta. (3)Dados obtidos por meio de análises químicas. digestível, multiplicado por 2,25 e carboidratos não fibrosos digestíveis, segundo Weiss (1999).

Os coeficientes de digestibilidade real da proteína bruta (DRPB) foram estimados utilizando-se valores de $0,229 \mathrm{~g} \mathrm{~kg}^{-0,75} \mathrm{dia}^{-1}$ para o nitrogênio metabólico fecal (NF), segundo Silva Sobrinho (1991):

DRPB $=[100($ PB fecal - 6,25NF) $] /$ PB consumida.

Os resultados foram analisados, estatisticamente, por meio de análises de variância e as médias foram comparadas pelo teste de Tukey a 5\% de probabilidade, utilizando-se o Sistema de Análises Estatístico e Genético - SAEG (Universidade Federal de Viçosa, 1998).

O modelo matemático foi o seguinte: $\mathrm{Y}_{\mathrm{ij}(\mathrm{k})}=\mathrm{m}+\mathrm{t}_{\mathrm{k}}+\mathrm{l}_{\mathrm{i}}+\mathrm{C}_{\mathrm{j}}+\mathrm{e}_{\mathrm{ij}(\mathrm{k})}$, em que $\mathrm{Y}_{\mathrm{ij}(\mathrm{k})}$ é a observação do tratamento $\mathrm{k}$ $(k=1,2, \ldots, 5)$, na linha $i(i=1,2, \ldots, 5)$, coluna $j(j=1,2, \ldots, 5)$; $\mathrm{m}$ é a constante geral; $\mathrm{t}_{\mathrm{k}}$ é o efeito do tratamento $\mathrm{k} ; \mathrm{l}_{\mathrm{i}}$ é o efeito da linha i; Cj é o efeito da coluna j; e e $\mathrm{e}_{\mathrm{ij}(\mathrm{k})}$ é o erro experimental associado à observação $Y_{\mathrm{ij}(\mathrm{k})}$.

\section{Resultados e Discussão}

Não houve efeito da substituição parcial do concentrado a base de milho moído e farelo de soja, pelos subprodutos estudados, sobre a digestibilidade aparente da matéria seca, da matéria orgânica, da proteína bruta, da fibra em detergente neutro, da fibra em detergente ácido, dos carboidratos totais e carboidratos não fibrosos (Tabela 3).

Tabela 3. Coeficientes (\%) de digestibilidade aparente da matéria seca (CDMS), matéria orgânica (CDMO) e proteína bruta (CDPB), de digestibilidade real da proteína bruta (CDRPB), e coeficientes de digestibilidade aparente da fibra em detergente neutro (CDFDN), fibra em detergente ácido (CDFDA), extrato etéreo (CDEE), carboidratos totais (CDCHT), carboidratos fibrosos (CDCF) e não fibrosos (CDCNF) em cabras leiteiras com consumo de dietas com inclusão de farelo de cacau ou torta de dendê(1).

\begin{tabular}{|c|c|c|c|c|c|c|c|}
\hline \multirow[t]{2}{*}{ Variável } & \multirow[t]{2}{*}{ Controle } & \multicolumn{2}{|c|}{ Farelo de cacau } & \multicolumn{2}{|c|}{ Torta de dendê } & \multirow[t]{2}{*}{ Média } & \multirow{2}{*}{$\begin{array}{l}\mathrm{CV} \\
(\%)\end{array}$} \\
\hline & & $15 \%$ & $30 \%$ & $15 \%$ & $30 \%$ & & \\
\hline CDMS & $69,26 \mathrm{a}$ & $66,07 \mathrm{a}$ & $60,51 \mathrm{a}$ & $67,86 a$ & $66,46 a$ & 66,03 & 8,22 \\
\hline CDMO & $\mathrm{a}$ & $68,35 \mathrm{a}$ & $3 a$ & $70,01 \mathrm{a}$ & & 33 & 7,54 \\
\hline CDPB & $66,31 \mathrm{a}$ & $58,60 \mathrm{a}$ & $43,73 a$ & $62,46 a$ & $65,91 \mathrm{a}$ & 59,40 & 19,63 \\
\hline CDRPB & 75 & $67,81 \mathrm{~b}$ & $67,53 \mathrm{~b}$ & $74,04 \mathrm{a}$ & $75,59 \mathrm{a}$ & 72,08 & 4,17 \\
\hline $\mathrm{CDF}$ & 53 , & $43,01 \mathrm{a}$ & $43,07 \mathrm{a}$ & $48,62 \mathrm{a}$ & $48,64 \mathrm{a}$ & 47,33 & 22,23 \\
\hline CDFDA & $49,44 a$ & $40,44 \mathrm{a}$ & $40,27 \mathrm{a}$ & $46,52 \mathrm{a}$ & $48,85 \mathrm{a}$ & 45,02 & 19,67 \\
\hline CDEE & $86,84 \mathrm{ab}$ & $84,84 \mathrm{~b}$ & $90,85 \mathrm{ab}$ & $88,37 \mathrm{ab}$ & $92,06 \mathrm{a}$ & 88,59 & 4,02 \\
\hline CDCHT & $70,11 \mathrm{a}$ & $66,60 \mathrm{a}$ & $61,48 \mathrm{a}$ & $67,25 \mathrm{a}$ & $65,27 \mathrm{a}$ & 66,14 & 8,04 \\
\hline CDCF & $54,04 \mathrm{a}$ & $44,59 \mathrm{a}$ & $42,29 a$ & $49,30 \mathrm{a}$ & $47,00 \mathrm{a}$ & 47,44 & 23,92 \\
\hline CDCNF & $80,17 \mathrm{a}$ & $82,24 \mathrm{a}$ & $79,95 \mathrm{a}$ & $81,71 \mathrm{a}$ & $82,17 \mathrm{a}$ & 81,25 & 7,40 \\
\hline
\end{tabular}

(1)Médias seguidas de mesma letra, na linha, não diferem entre si pelo teste de Tukey a 5\% de probabilidade. 
Os resultados deste trabalho, em relação à digestibilidade aparente das dietas com torta de dendê, estão de acordo com os citados por Rodrigues Filho et al. (1996). Esses autores, ao avaliarem a torta de dendê, em substituição ao farelo de trigo, em concentrados $(0 \%$, $30 \%, 60 \%$ e $100 \%$ ) na dieta de ovinos deslanados, não observaram diferenças no coeficiente de digestibilidade da MS, MO e PB.

Os coeficientes aparentes de digestibilidade da MS e MO encontrados podem ser considerados relativamente baixos, quando comparados com os valores observados por Carvalho et al. (2002). Esses autores estudaram níveis crescente de FDN proveniente da forragem, na dieta de cabras Alpinas, e encontraram coeficientes de digestibilidade aparente da MS e MO que decresceram, linearmente, de $75,23 \%$ para $69,63 \%$ e de a $76,30 \%$ para $70,19 \%$, respectivamente, para proporções de volumoso na MS que variaram de 28,8\% a 69,14\%.

Quanto a esses valores menores, a qualidade da silagem de milho deve ser levada em consideração (Tabela 1), pois parte das espigas foram comercializadas e a menor proporção de grãos, provavelmente, contribuiu para a diminuição da digestibilidade da MS. Mayer et al. (1999), ao utilizarem silagem de milho com baixa proporção de grãos, na alimentação de vacas em lactação, observaram digestibilidade aparente da MS inferior a $50 \%$.

Outras considerações devem também ser feitas em relação à fibra efetiva, pois o elevado conteúdo de partículas reduzidas, provenientes dos concentrados, favoreceu o consumo de MS (média de 4,16\% do peso do animal vivo), em função da maior taxa de remoção do rúmen, o que resultou em menos tempo disponível para os microorganismos digerirem os alimentos. Bava et al. (2001), ao estudarem dietas com ausência de forragens na alimentação de cabras, observaram que, em geral, os coeficientes aparentes de digestibilidade foram menores que nas dietas com forragem. Os autores consideraram o elevado consumo das dietas, com ausência de forragem, como um dos prováveis fatores que influenciaram negativamente a digestibilidade aparente.

A semelhança entre os tratamentos, quanto ao coeficiente de digestibilidade da MS e da MO, deve-se ao consumo de FDN (média de 40,23 $\mathrm{g} \mathrm{kg}^{-0,75} \mathrm{dia}^{-1}$ ), pois as inclusões dos subprodutos não foram suficientes para elevar os teores da fibra em níveis que pudessem influenciar a digestibilidade da MS e da MO. Também a semelhança da relação entre o consumo de nutrientes digestíveis totais (NDT) e da proteína, com o da MS (Tabela 4), pode explicar estes resultados.

Entre os tratamentos, a digestibilidade aparente da PB não foi afetada pela inclusão dos subprodutos. No entanto, após estimativa da proteína metabólica fecal, foram constatadas diferenças entre os tratamentos, na digestibilidade real da PB. As dietas com farelo de cacau apresentaram menor digestibilidade real da PB.

$\mathrm{O}$ fato de os coeficientes aparentes da PB não terem sido estatisticamente diferentes deve-se à proteína metabólica fecal que elevou o coeficiente de variação, diminuindo a eficiência dos testes de comparação entre as médias. Essa influência foi maior para o tratamento com $30 \%$ de inclusão de farelo de cacau, em virtude de menor consumo de PB observado (38,8\% inferior ao tratamento controle). Carvalho et al. (1995), ao justificarem o aumento da digestibilidade aparente da PB, consideraram que com aumento dos níveis da PB nas rações, houve redução do efeito do nitrogênio metabólico fecal sobre aquela fração.

Os menores valores para a digestibilidade real da PB, possivelmente, devem-se ao teor de digestibilidade da fibra insolúvel em detergente neutro. No tratamento com $30 \%$ de farelo de cacau, houve maior consumo de FDN proveniente da forragem, visto que, quando as cabras reviravam o alimento, o concentrado acumulava-se no fundo do cocho, pelas diferenças físicas de densidade e tamanho - semelhante às observações realizadas por Silva et al. (1999) -, facilitando a preensão seletiva dos

Tabela 4. Porcentuais de proteína (PB), proteína insolúvel em detergente neutro (PIDN), nutrientes digestíveis totais (NDT), fibra em detergente neutro (FDN), fibra em detergente ácido (FDA), carboidratos totais (CHT), carboidratos não fibrosos (CNF), extrato etéreo (EE), na matéria seca consumida por cabras alimentadas com dietas com farelo de cacau ou torta de dendê(1).

\begin{tabular}{|c|c|c|c|c|c|c|c|}
\hline \multirow[t]{2}{*}{ Variável } & \multirow[t]{2}{*}{ Controle } & \multicolumn{2}{|c|}{ Farelo de cacau } & \multicolumn{2}{|c|}{ Torta de dendê } & \multirow[t]{2}{*}{ Média } & \multirow[t]{2}{*}{$\mathrm{CV}(\%)$} \\
\hline & & $15 \%$ & $30 \%$ & $15 \%$ & $30 \%$ & & \\
\hline PB & $13,54 a$ & $13,31 \mathrm{a}$ & $11,48 \mathrm{a}$ & $11,22 \mathrm{a}$ & $12,83 \mathrm{a}$ & 12,48 & 11,47 \\
\hline $\mathrm{PIDN}^{(2)}$ & $17,17 \mathrm{a}$ & $18,21 \mathrm{a}$ & $23,36 \mathrm{a}$ & $16,60 \mathrm{a}$ & $18,19 \mathrm{a}$ & 18,71 & 36,19 \\
\hline NDT & $66,79 a$ & $60,84 a$ & $58,71 \mathrm{a}$ & $60,92 a$ & $62,24 a$ & 61,90 & 7,99 \\
\hline FDN & $33,04 b$ & $34,34 b$ & $43,12 \mathrm{a}$ & $37,09 \mathrm{ab}$ & $39,97 \mathrm{ab}$ & 37,51 & 9,95 \\
\hline FDA & $13,75 \mathrm{c}$ & $15,65 \mathrm{bc}$ & $21,43 \mathrm{a}$ & $16,82 b$ & $22,46 \mathrm{a}$ & 18,02 & 7,70 \\
\hline CHT & $73,90 \mathrm{a}$ & $71,65 \mathrm{a}$ & $72,47 \mathrm{a}$ & $72,01 \mathrm{a}$ & $71,85 \mathrm{a}$ & 72,37 & 4,01 \\
\hline $\mathrm{CNF}$ & $45,15 \mathrm{a}$ & $42,14 \mathrm{ab}$ & $36,32 \mathrm{c}$ & $39,12 b c$ & $37,16 \mathrm{bc}$ & 39,98 & 6,85 \\
\hline $\mathrm{EE}$ & $3,56 \mathrm{~b}$ & $3,71 \mathrm{ab}$ & $5,03 \mathrm{a}$ & $3,79 \mathrm{ab}$ & $3,65 \mathrm{ab}$ & 3,95 & 17,79 \\
\hline
\end{tabular}

(1)Médias seguidas de mesma letra, na linha, não diferem entre si pelo teste de Tukey a 5\% de probabilidade; valores obtidos: [100(nutriente na dieta oferecida - nutriente na sobra)]/consumo de MS. (2)Porcentual da proteína bruta. 
ingredientes da dieta. Nesse tratamento, ao contrário do ocorrido nos demais, houve seleção da silagem e rejeição do concentrado. Com o aumento dos teores de FDN da forragem na MS consumida, ocorreu redução na digestibilidade da proteína (Carvalho et al., 2002).

Quanto ao tratamento com 15\% de inclusão de farelo de cacau, deve-se considerar os altos teores de PB insolúvel em detergente neutro (Tabela 1) desse subproduto, e a baixa digestibilidade da FDN observada nos tratamentos.

Os valores dos coeficientes aparentes de digestibilidade da FDN e FDA foram baixos, comparados aos observados por Carvalho et al. (2002).

Esses baixos coeficientes de digestibilidade da FDN e da FDA (Tabela 4) não parecem estar relacionados à disponibilidade de nitrogênio, pois os teores estavam acima das recomendações mínimas (acima de 7\% de PB na dieta), nem parecem estar relacionados à disponibilidade de energia e à sincronização desta com os compostos nitrogenados, o que poderia afetar a síntese de proteína microbiana. Os baixos valores, observados na digestibilidade aparente da fibra, parecem ter ocorrido em função da alta disponibilidade dos carboidratos não fibrosos, pois estes, apesar de suprirem energia para os microorganismos ruminais, podem ter efeito negativo sobre sua atividade celulolítica, inibindo a digestão da fibra, principalmente pela redução do pH ruminal (Gonçalves et al., 2001).

Como os carboidratos não fibrosos apresentam alta digestibilidade, as diferenças nos coeficientes de digestibilidade aparente, observadas para a mesma relação de volumoso:concentrado na dieta, dependem da qualidade e quantidade da FDN.

Esperava-se maior digestibilidade aparente da FDN no tratamento com 30\% de farelo de cacau, graças ao maior percentual de FDN na MS consumida (Tabela 4), em razão do aumento da digestibilidade ruminal da fibra, promovido pelas condições ruminais que favorecem o desenvolvimento de microorganismos fibrolíticos (Carvalho et al., 2002). Além da qualidade da silagem (Tabela 1), parece ter havido efeito depressivo, em função dos teores de ácidos graxos, visto que percentuais superiores a $5 \%$ de extrato etéreo na MS (Tabela 4) podem afetar a digestibilidade da fibra (Mora et al., 1996).

As dietas não diferiram quanto à digestibilidade de carboidratos totais, carboidratos não fibrosos e fibrosos. Considerando-se que o percentual de carboidratos totais na MS consumida (Tabela 4) foram semelhantes, e que os teores de carboidratos não fibrosos apresentaram diferenças significativas, esperava-se que houvesse alterações na digestibilidade dos carboidratos, menores para 30\% de FC, em função dos teores de ácidos graxos (Tabela 4), pois, dentre os efeitos dos lipídios na fermentação ruminal, a redução da digestão dos carboidratos fibrosos tem sido o mais relatado.

A redução na concentração de carboidratos não fibrosos, em razão da seleção do volumoso em detrimento do concentrado, observado no tratamento com $30 \%$ de FC, não afetou a digestibilidade aparente dos carboidratos. Essas semelhanças podem estar relacionadas à redução dos carboidratos não fibrosos, no coeficiente de digestibilidade, em razão do alto consumo de concentrados nos demais tratamentos.

O coeficiente médio de digestibilidade do extrato etéreo (EE) foi ligeiramente superior aos 76,84\% observados por Carvalho et al. (2002), e foi semelhante ao coeficiente médio encontrado por Solaiman et al. (2002), que estudaram a substituição do milho e farelo de soja do concentrado, pelo caroço de algodão, na alimentação de cabras. Sampelayo et al. (2002), encontraram valores superiores ao utilizar cabras Granadina, em lactação, alimentadas com dietas compostas de 50\% de forragem e $50 \%$ de mistura, concentrada com diferentes percentuais de gordura.

Houve diferença na digestibilidade aparente do EE apenas entre os tratamentos com 15\% de FC e 30\% de TD. Essa diferença não pode ser explicada pelo consumo de EE (81,06 g e 81,23 $\mathrm{g} \mathrm{dia}^{-1}$ de EE para os tratamentos com $15 \%$ de FC e $30 \%$ de TD), nem pelo percentual deste na dieta oferecida (Tabela 2), nem pela proporção na MS ingerida (Tabela 4), pois não houve diferenças para essas variáveis entre esses tratamentos.

Tal resultado poderia ser considerado contraditório, pois a literatura indica efeito positivo na digestibilidade do EE, com o incremento deste na dieta (Sampelayo et al., 2002; Solaiman et al., 2002). Oliveira Junior et al. (2000) constataram efeito quadrático sobre o coeficiente de digestibilidade aparente do EE, que aumentou devido à menor representatividade da gordura fecal endógena, em relação à gordura fecal oriunda da dieta, com o aumento do EE dietético. Posteriormente, observou-se uma redução do coeficiente, indicando que o limite de eficiência de utilização da gordura foi excedido. Essa eficiência, segundo Palmquist (1989) se dá em função da fibra insolúvel em detergente ácido (máxima eficiência, com 21\% de FDA na dieta total). 
Analisando-se os teores de EE e de FDA na MS consumida (Tabela 4), pode-se constatar que não houve diferença entre os tratamentos com $15 \%$ de FC e $30 \%$ de TD, para os teores de EE. Os percentuais de FDA da dieta com 30\% TD foram maiores e próximos aos valores estabelecidos como aqueles que permitem maior eficiência de utilização dos ácidos graxos.

\section{Conclusões}

1. A inclusão de farelo de cacau e torta de dendê, até $30 \%$ de substituição parcial ao milho e farelo de soja, no concentrado padrão, não afeta a digestibilidade aparente da matéria seca da ração completa, em cabras em lactação.

2. Os subprodutos têm viabilidade de uso, como alternativa na dieta de cabras em lactação, substituindo parte do concentrado padrão à base de milho moído e farelo de soja.

\section{Agradecimentos}

Ao $\mathrm{CNPq}$, pelas bolsas de pesquisa concedidas a Gleidson Giordano Pinto de Carvalho e Andréia Santos Cezário; à Fapesb, pela bolsa de pesquisa concedida a Cibele Costa Santos.

\section{Referências}

BAVA, L.; RAPETTI, L.; CROVETTO G.M.; TAMBURINI, A.; SANDRUCCI, A.; GALASSI, G.; SUCCI, G. Effects of a non forage diet on milk production, energy, and nitrogen metabolism in dairy goats throughout lactation. Journal of Dairy Science, v.84, p.24502459, 2001.

BRASIL. Ministério da Agricultura e Abastecimento. Compêndio Brasileiro de Alimentação Animal. Brasília: Sindirações/Anfar; CBNA; SDR/MA, 1998. 12p.

CARVALHO, F.F.R.; QUEIROZ, A.C. de; RODRIGUES, M.T.; FONTES, C.A. de A. Efeitos de níveis crescentes de proteína bruta sobre a digestibilidade dos nutrientes em cabras lactantes. Revista da Sociedade Brasileira de Zootecnia, v.24, p.852-862, 1995.

CARVALHO, S.; RODRIGUES, M.T.; BRANCO, R.H.; RODRIGUES, C.A.P.F.; GUIMARÃES, V.P.; FACÍOLA, A.P.; SILVA, C. da; LOBÃO, E. de S.P. Digestibilidade aparente em cabras alpinas em lactação alimentadas com dietas contendo diferentes níveis de fibra em detergente neutro. In: REUNIÃO ANUAL DA SOCIEDADE BRASILEIRA DE ZOOTECNIA, 39., 2002. Recife. Anais. Recife, 2002. 1 CD-ROM. Nutrição de Ruminantes.

CHIN, F.Y. Utilization of palm kernel cake (PKC) as feed in Malaysia. In: ANIMAL PRODUCTION AND HEALTH COMMISSION FOR ASIAAND THE PACIFIC, 26., 2002, Subang Jaya, Malaysia. Anais. Subjang Jaya, Malaysia: FAO, 2002. p.137-144.
GONÇALVES, A.L.; LANA, R. de P.; RODRIGUES, M.T.; VIEIRA, R.A.M.; QUEIROZ, A.C. de; HENRIQUE, D.S. Degradabilidade ruminal da matéria seca e da fibra em detergente neutro de alguns volumosos utilizados na alimentação de cabras leiteiras, submetidas a dietas com diferentes relações volumosos:concentrados. Revista da Sociedade Brasileira de Zootecnia, v.30, p.1893-1903, 2001.

IBGE. Produção agrícola municipal (PAM). Disponível em: http://www.sidra.ibge.gov.br. Acesso em: mar. 2004.

MARTINS, A. de S.; PRADO, I.N. do; ZEOULA, L.M.; BRANCO, A.F.; NASCIMENTO, W.G. do. Digestibilidade aparente de dietas contendo milho ou casca de mandioca como fonte energética e farelo de algodão ou levedura como fonte protéica em novilhas. Revista da Sociedade Brasileira de Zootecnia, v.29, p.269-277, 2000.

MAYER, L.R.R.; SILVA, J.F.C. da; VALADARES FILHO, S. de C.; CAMPOS, J.M. de S. Rações com diferentes teores de proteína degradada no rúmen, para vacas em lactação: 2 . Taxa de passagem, digestibilidade e energia líquida da silagem de milho. Revista da Sociedade Brasileira de Zootecnia, v.26, p.824-831, 1999.

MORA, P.J.G.; VALADARES FILHO, S. de C.; LEÃO, M.I. Digestibilidade aparente dos nutrientes e energia líquida da silagem de milho (Zea mays L.) para vacas lactantes. Revista da Sociedade Brasileira de Zootecnia, v.25, p.357-367, 1996.

NATIONAL RESEARCH COUNCIL (Washington, Estados Unidos). Nutrient requirements of goats: angora, dairy, and meat goats in temperate and tropical countries. Washington, D.C.: National Academy Press, 1981. 84p.

OLIVEIRA JUNIOR, R.C. de; SUSIN, I.; PIRES, A.V.; SIMAS, J.M.C. de. Efeitos de níveis de grão de soja na dieta de cabras: 2. Produção e composição do leite. In: REUNIÃO ANUAL DA SOCIEDADE BRASILEIRA DE ZOOTECNIA, 37., 2000, Viçosa. Anais. Viçosa, 2000. 1 CD-ROM. Nutrição de Ruminantes.

PALMQUIST, D.L. Suplementação de lipídeos para vacas em lactação. In: SIMPÓSIO SOBRE NUTRIÇÃO DE RUMINANTES, 6., 1989, Piracicaba. Anais. Piracicaba: Fealq, 1989. p.11-25.

PIRES, A.J.V.; VIEIRAS, V.F.; SILVA, F.F. da; VELOSO, C.M.; CAVALHO, G.G.P. de; PEIXOTO, C.A. de M. Farelo de cacau (Theobroma cacao) na alimentação de novilhos. In: REUNIÃO ANUAL DA SOCIEDADE BRASILEIRA DE ZOOTECNIA, 39., 2002, Recife. Anais. Recife, 2002. 1 CD-ROM. Nutrição de Ruminantes.

RODRIGUES FILHO, J.A.; CAMARÃO, A.P.; BATISTA, H.A.M.; AZEVEDO, G.P.C. de; BRAGA, E. Níveis de torta de dendê em substituição ao farelo de trigo no consumo voluntário e digestibilidade de concentrados. In: REUNIÃO DA SOCIEDADE BRASILEIRA DE ZOOTECNIA, 35., 1996, Fortaleza. Anais. Fortaleza, 1996. p.292-293.

SAMPELAYO, M.R.S.; PEREZ, L.; ALONSO, J.J.M.; EXTREMERA, F.G.; BOZA, J. Effects of concentrates with different contents of protected fat rich in PUFAs on the performance of lactating Granadina goats. 1. Feed intake, nutrient digestibility, N and energy utilization for milk production. Small Ruminat Research, v.43, p.133-139, 2002.

SILVA, D.J.; QUEIROZ, A.C. de. Análise de alimentos: métodos químicos e biológicos. 3.ed. Viçosa: UFV, 2002. 235p. 
SILVA, J.H.V. da; RODRIGUES, M.T.; CAMPOS, J. Desempenho de cabras leiteiras recebendo dietas com diferentes relações volumoso:concentrado. Revista da Sociedade Brasileira de Zootecnia, v.28, p.1412-1418, 1999.

SILVA, L. das D.F. da; EZEQUIEL, J.M.B.; AZEVEDO, P.S.; CATTELAN, J.W.; BARBOSA, J.C.; RESENDE, F.D. de; CARMO, F.RG. do. Digestão total e parcial de alguns componentes de dietas contendo diferentes níveis de casca de soja e fonte de nitrogênio, em bovinos. Revista da Sociedade Brasileira de Zootecnia, v.31, p.1258-1268, 2002.

SILVA SOBRINHO, A.G.; RODRIGUES, M.T.; GARCIA, J.A.; SILVA, J.F.C. da; VALADARES, S. de C. Composição corporal e exigências nutricionais de proteínas para cabras em lactação. Revista da Sociedade Brasileira de Zootecnia, v.20, p.614-631, 1991.
SNIFFEN, C.J.; VAN SOEST, P.J. A net carbohydrate and protein system for evaluating cattle diets: 2. Carbohydrate and protein availability. Jornal of Animal Science, v.70, p.3562-3577, 1992. SOLAIMAN, S.G.; SMOOT, Y.P.; OWENS, F.N. Impact of EasiFlo cottonseed on feed intake, apparent digestibility, and rate of passage by goats fed a diet containing 45\% hay. Journal of Animal Science, v.80, p.805-811, 2002.

UNIVERSIDADE FEDERAL DE VIÇOSA. SAEG - sistema para análises estatísticas e genéticas: versão 8.0. Viçosa: Fundação Arthur Bernardes, 1998. Apostila.

WEISS, W. Energy prediction equations for ruminant. In: CORNELL NUTRITION CONFERENCE FOR FEED MANUFACTURES, 61., 1999, Ithaca. Proceedings. Ithaca: Cornell University, 1999. p.176-185.

Recebido em 15 de abril de 2004 e aprovado em 24 de novembro de 2004 